\title{
Experimental investigation on the cavity-based scramjet model
}

\author{
GU HongBin ${ }^{\dagger}$, CHEN LiHong \& CHANG XinYu \\ Key Laboratory of High Temperature Gas Dynamics, Institute of Mechanics, Chinese Academy of Sciences, Beijing 100190, China
}

The present work focused on improving the engine performance with different fuel equivalence ratios and fuel injections. A scramjet model with strut/cavity integrated configurations was tested under Mach 5.8 flows. The results showed that the strut may sreve as an effective tool in a kerosene-fueled scramjet. The integration of strut/cavities also had great effect on stablizing the combustion in a wide range of fuel equivalence ratio. The one-sdimensional analysis method was used to analyze the main characteristics of the model. The two-stage fuel injection should have better performance in increasing the chemical reaction rate in the first cavity region.

scramjet, combustor, cavity, performance

Scramjet engine has been investigated over fifty years and several engines have been flight-tested in the past few years ${ }^{[1,2]}$. Hydrocarbon fuels such as kerosene have high potential utilization in the future hypersonic transportations for the merit of easy storable and high energy density. However the disadvantages of kerosene are the long ignition delay time and low chemical reaction rate. The low combustion efficiency in a supersonic flow is a major shortage for the kerosene fueled scramjet ${ }^{[3]}$.

The ignition delay of kerosene is usually longer than the flow residence time in scramjet combustor, so the kerosene must be ignited by additional method such as torch or cavity, etc. ${ }^{[4,5]}$. Vinogradov et al. ${ }^{[6]}$ used cavity and integrated pilot hydrogen to ignite and stabilize combustion in a two-dimensional scramjet at low hydrogen equivalence ratio $(E R=0.1)$. In some cases, combustion continued after pilot hydrogen flow was terminated. Yu et al. ${ }^{[7,8]}$ investigated the performance of supersonic combustion with different cavities and injection/ cavity integration configurations in the direct-connect supersonic combustion test facility. The stable supersonic combustion and better combustion efficiency were obtained using cavity with pilot hydrogen $(E R \approx 0.1)$ than before. The characters of cavity flame-holder were sensitive to the flow condition and fuel feeding scheme ${ }^{[9]}$.
Only when the fuel injected into the cavity was properly tuned, minimum flame oscillations can be obtained ${ }^{[10,11]}$. Since deeper fuel penetration is required for increasing combustion efficiency at high equivalence ratio, the fuel penetration depth becomes an obstacle when fuel is injected from the wall ${ }^{[12]}$. The scramjet engine with a central strut was designed to enhance mixing in the core region of the flow. The better performance was obtained by hydrogen injected from the strut under Mach 8 conditions $^{[13]}$. However there was no systematic report on the kerosene injection parameters effect on the performance of the cavity-based scramjet engine in combination with the strut.

In supersonic combustor, the finite rate kinetics is strongly coupled with the fluid mechanics. A high thrust increment was obtained by the staged fuel injections in a dual-mode combustor ${ }^{[14]}$ and a diverging supersonic combustor $^{[15]}$, but the performance strongly depended on the injector location. Therefore studies are essential to obtain the better heat release and pressure distribution through staged fuel injections ${ }^{[16]}$.

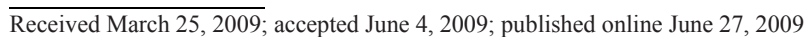
doi: 10.1007/s11434-009-0460-4

Corresponding author (email: guhb@imech.ac.cn)

Supported by the National Natural Science Foundation of China (Grant Nos. 90305022, 10525212)
} 
In this paper, the study was based on our previous research of the scramjet model with different combustor configurations. The effects of fuel injections location and two-stage fuel injections were investigated in free-jet tunnel. Mechanism of two-stage fuel injections gives clues of improving scramjet performance.

\section{Test facility and scramjet model}

\subsection{Test facility and instruments}

The test facility used in scramjet experiments is a highenthalpy free-jet tunnel (Figure 1), the so-called HPTF (hypersonic propulsion test facility). It provides typical test conditions as Mach number $M a \approx 5.8$, total pressure $P_{\mathrm{t}} \approx 4.5 \mathrm{MPa}$, total temperature $T_{\mathrm{t}} \approx 1900 \mathrm{~K}$ and mass flow rate $4 \mathrm{~kg} / \mathrm{s}$ by a rectangular facility nozzle with the exit of $300 \mathrm{~mm}$ in width and $190 \mathrm{~mm}$ in height. The pressure inside the test cabin is $4 \mathrm{kPa}$ which duplicates the engine entrance pressure condition of $25 \mathrm{~km}$ altitude, achieved by a single staged triple-nozzles air ejector with $40 \mathrm{~kg} / \mathrm{s}$ mass flow rate.

The static pressures along the model are measured by PSI 8400 pressure scanner with 128 channels. The six components of force balance are used to measure the thrust increment of engine.

\subsection{Scramjet model}

A sidewall compression scramjet engine was used in the tests. The engine shown in Figure 2 is rectangular at the entrance and exit, and the duct is $0.2 \mathrm{~m}$ wide, $0.07 \mathrm{~m}$ high and $1.8 \mathrm{~m}$ long. It is divided into four sections: inlet, isolator, combustor and nozzle. The compression angle of inlet is $7^{\circ}$. A cowl is at $474 \mathrm{~mm}$ from the leading edge, and the thickness of the strut is $22 \mathrm{~mm}$. The combustor is $800 \mathrm{~mm}$ long with $1.5^{\circ}$ divergence angle. The nozzle is $300 \mathrm{~mm}$ long with straight walls. The strut with staggered wedge tail serves as a compression surface at the inlet as well as a fuel injector in the combustor. Recessed cavities functioning as the flame-holder in the combustor are used, as shown in Figure 3. Both strut and cavity generate variant vortexes that help the mixing and combustion, as well as extending the fuel residence time.

\section{Results and discussion}

The experimental investigations were carried out with different fuel injection locations and combinations of the fuel injections, as shown in Figure 3. The kerosene was injected perpendicularly from the strut or/and sidewall. There were three positions at the strut, named as S1, S2, $\mathrm{S} 3$, and two positions on the sidewall, $\mathrm{C} 1$ and $\mathrm{C} 2$. There are 5 holes in each position, and the diameter of holes is $0.3 \mathrm{~mm}$. It is distributed with an equal distance of 14 $\mathrm{mm}$. The pilot hydrogen is injected from $\mathrm{H} 1$ and $\mathrm{H} 2$. The equivalence ratios of pilot hydrogen were the same for all tests, $E R_{\mathrm{H} 1}=0.05, E R_{\mathrm{H} 2}=0.025$.

Several grades of the fuel equivalence ratios were tested to research the effect on the engine performance. The static pressure distribution along the model can indicate the combustion process inside the engine, and the thrust increment can evaluate the engine performance.

\subsection{Fuel injection from strut}

Figure 4 shows the pressure distributions along the scramjet model with fuel injected at S3 and H1. The $X$-coordinate is the dimensionless length normalized by the inlet length $(474 \mathrm{~mm}), X / X_{0}=1$ means the position of the cowl. The $Y$-coordinate is the dimensionless pressure normalized by the static pressure of the incoming flow $(2.7 \mathrm{kPa})$.

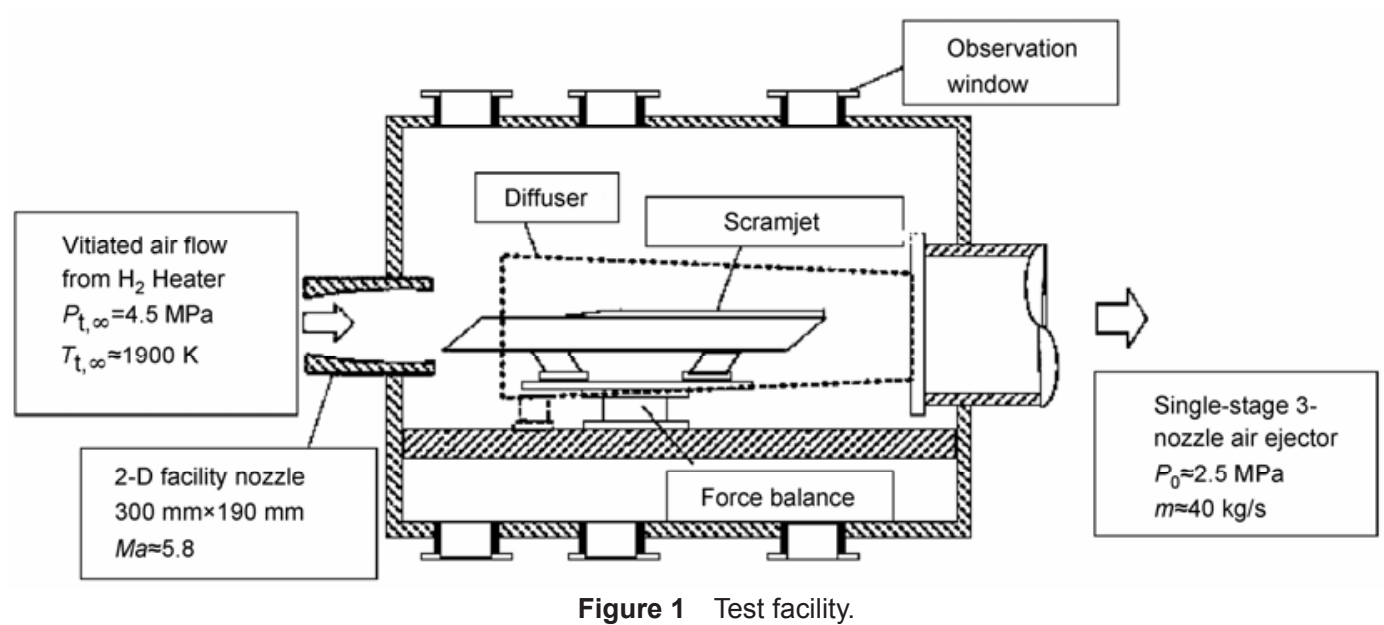




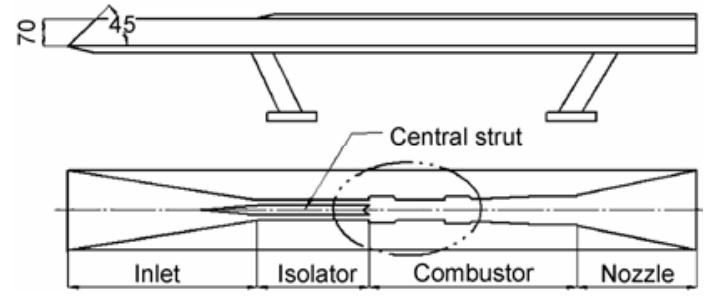

Figure 2 Sketch of the scramjet model.

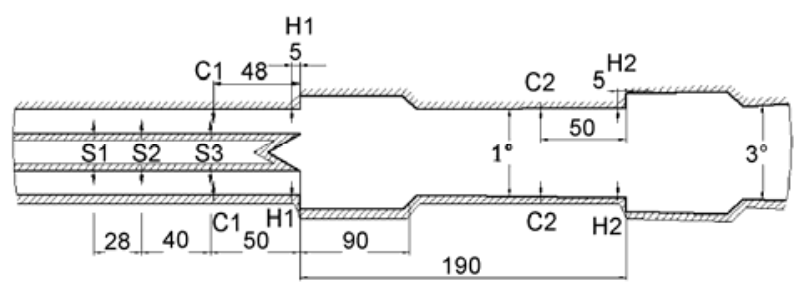

Figure 3 Sketch of fuel injection configuration.

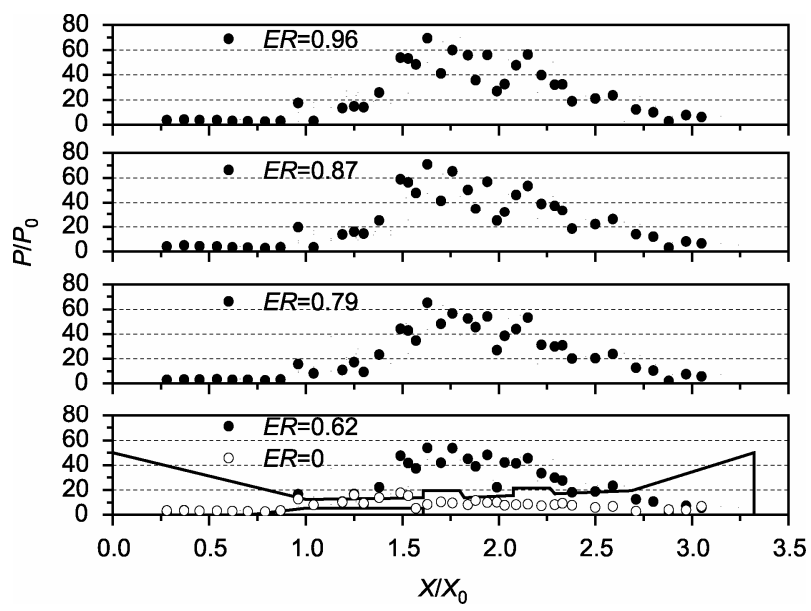

Figure 4 Pressure distributions along the scramjet model with different equivalence ratios (fuel injection: S3).

The hollow scatter is the case without fuel and solid scatters denote different equivalence ratios. The position of peak pressure is at the region of the first cavity, the value increases with the equivalence ratio until the value reaches about 0.87 , and then the peak pressure has little drop when $E R=0.96$. Figure 5 shows the corresponding thrust increment $(\Delta T)$, which increases with the fuel equivalence ratio until $E R=0.87$, and then the thrust increment decreases a little when $E R=0.96$.

The distributions of the static pressure are similar for different fuel equivalence ratios. The zigzag corresponds to the shock wave reflection. The inlet static pressure hardly changes. The pressure ratio at the exit of isolator is from 2.0 to 3.0 , and therefore the flow inside the isolator maintains supersonic at all test conditions. The combustion is stable under different fuel equivalent ra- tios. The similar pressure profile suggests the combustion processes are similar, but the heat release or chemical reaction rate increases at high fuel equivalence ratio. Since the method of changing fuel equivalence ratio is changing the injection pressure at the same fuel holes, the high equivalence ratio may induce better mixing due to higher pumping pressure and stronger interaction between fuel injection with main flow. Therefore, when equivalence ratio increases, more fuel joins the reaction or the combustion efficiency improves due to better mixing. The thrust increases with equivalence ratio to a special value, which has relation to the combustor configurations. The fuel mixing mainly depends on the shear layer generated from cavity front or strut, but the fuel penetration depth changes a little at high movement ratio. That induces local mixing rate to be saturated, and also the combustion efficiency approaches a limitation, so there are few differences between $E R=0.87$ and $E R=0.96$. The pressure and thrust results injected from $\mathrm{S} 2$ are similar to $\mathrm{S} 3$.

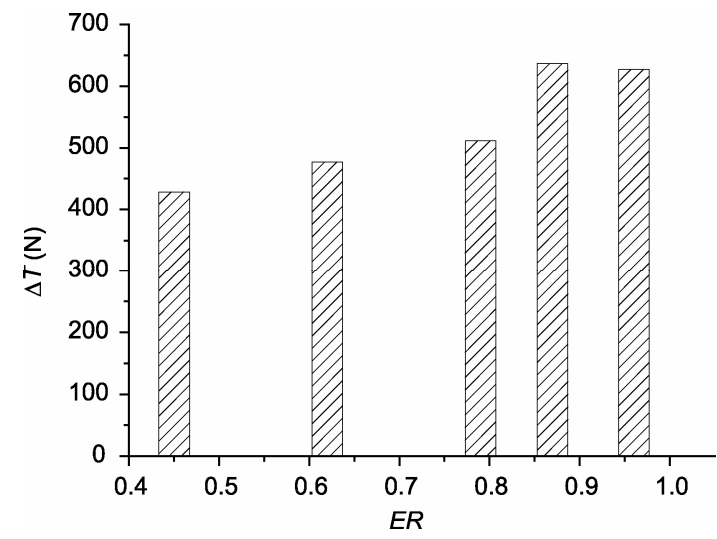

Figure 5 Thrust increment with fuel equivalence ratios (fuel injection: S3).

\subsection{Fuel injection from sidewall}

Figure 6 shows the pressure distribution along the model with fuel injected at $\mathrm{C} 1$ and $\mathrm{H} 1$. The pressure distribution resembles the case of S3. It indicates that the cavity is the main region for heat release. The maximum pressure is lower than the case of $\mathrm{S} 3$ at the approximate equivalence ratio (0.88). The better performance shows that the advantage of fuels is injected from strut.

Figure 7 shows that the thrust increments change with fuel equivalence ratio. The thrust increment increases with fuel equivalence ratio until $E R=0.8$, and then decreases when $E R=0.88$. The maximum thrust increment is lower than the case of S3. According to the results of 


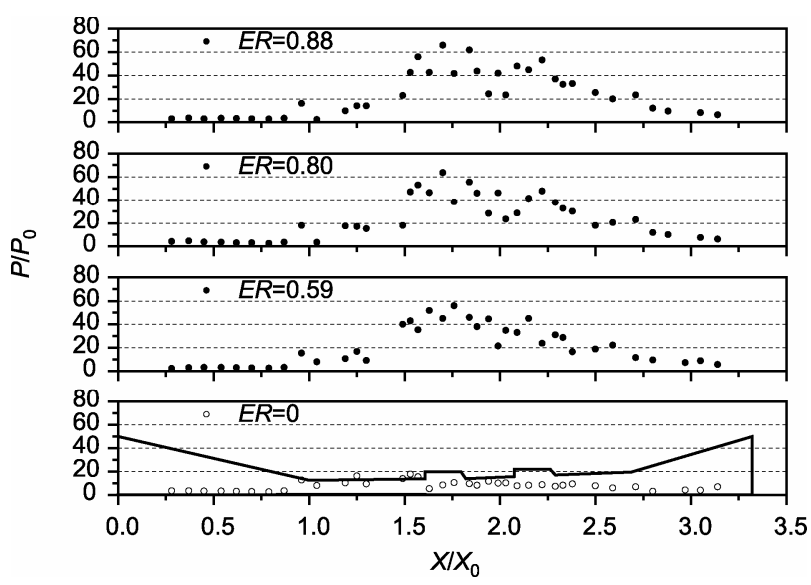

Figure 6 Pressure distributions along the scramjet model (fuel injection: C1).

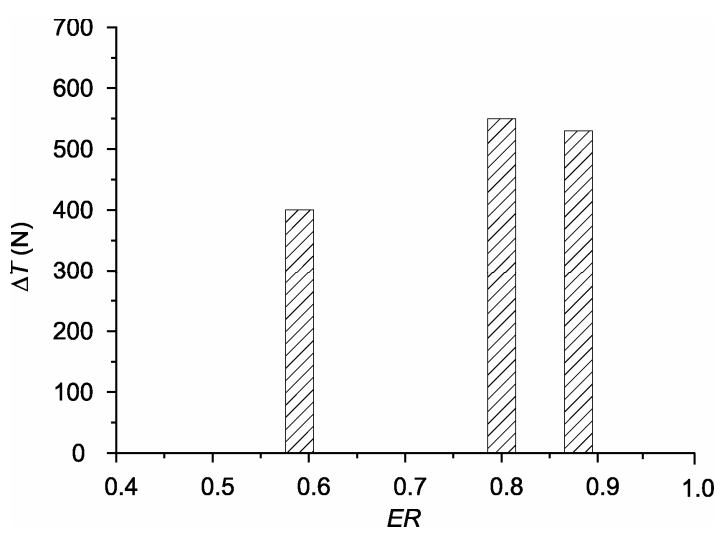

Figure 7 Thrust increment with fuel equivalence ratios (fuel injection: C1).

pressure, the reason may be that the fuel injected from sidewall decreases the flow speed of main flow, then decreases counter flow Mach number of shear layer, and finally influences the mixing process. However fuel injected from strut can avoid disturbing the initiation of shear layer. Therefore it can obtain better performance with fuel injected from strut.

\subsection{Fuel injections from both sidewall and strut}

In order to get better performance, the combinations of the fuel injections are used for spatial fuel distribution. Figure 8 shows the static pressure results with two-stage fuel injections, and the fuel equivalence ratios are shown in Table 1. The following three cases have almost the same equivalence ratios but different injection positions. The highest pressure is the case of $\mathrm{S} 2+\mathrm{C} 2$, the next is the fuel injection from $\mathrm{S} 2+\mathrm{C} 1$, and the lowest is the case of $\mathrm{C} 1+\mathrm{C} 2$.

Comparing the pressure results in the above cases, the static pressure with two-stage fuel injection at $\mathrm{S} 2+\mathrm{C} 2$ is higher than whichever single fuel injection cases. The

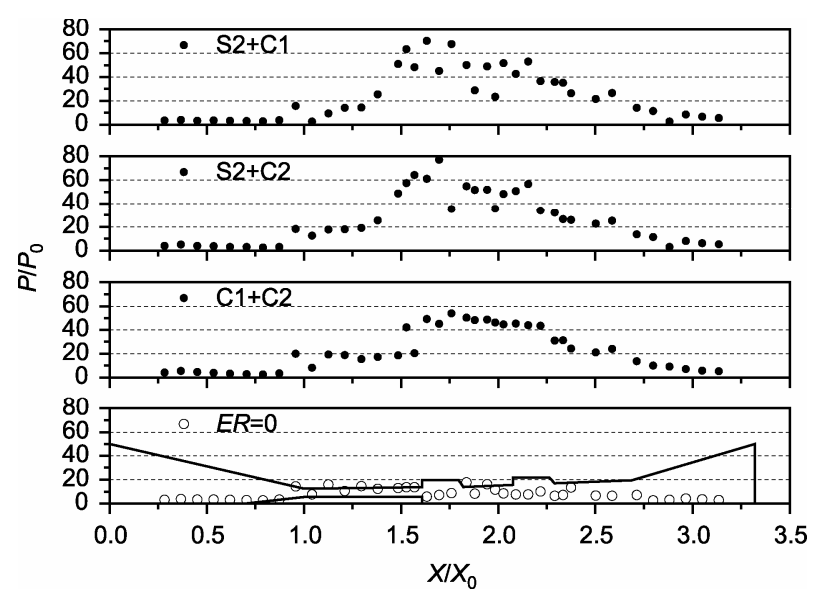

Figure 8 Pressure distributions along the scramjet model with two-stage fuel injections.

Table 1 Fuel equivalence ratios of two-stage fuel injections

\begin{tabular}{ccccc}
\hline Cases & $\mathrm{S} 2$ & $\mathrm{C} 1$ & $\mathrm{C} 2$ & Total $E R$ \\
\hline$(\mathrm{S} 2+\mathrm{C} 2)$ & 0.79 & & 0.32 & 1.11 \\
$(\mathrm{~S} 2+\mathrm{C} 1)$ & 0.76 & 0.36 & & 1.12 \\
$(\mathrm{C} 1+\mathrm{C} 2)$ & & 0.75 & 0.33 & 1.08 \\
\hline
\end{tabular}

case injected at $\mathrm{S} 2+\mathrm{C} 1$ is close to the case only injected at $\mathrm{S} 3$, but higher than $\mathrm{C} 1$. The case injected at $\mathrm{C} 1+\mathrm{C} 2$ is close to the case only injected at $\mathrm{C} 1$, and even the total equivalence ratio is higher than it. The results indicate that the second fuel injection has little effect on pressure distribution along the model, because the local concentration of oxygen might be low for insufficient diffusion of a great amount of reactants at the second cavity region.

The thrust results are shown in Figure 9, and the line paralleled to the $X$-coordinate represents the total drag of scramjet model without fuel. It includes the uninstalled engine drag and support configurations drag. The results indicate that two-stage fuel injections obtain positive thrust under test condition and higher thrust increment than other cases.

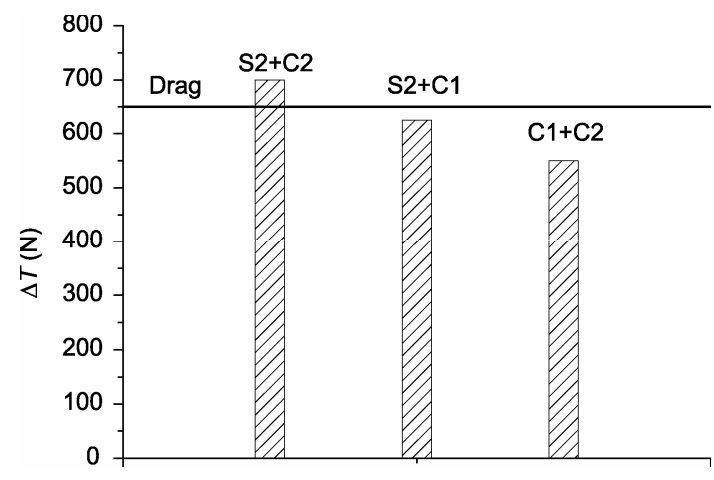

Figure 9 Thrust increment with two-stage fuel injections. 


\section{Numerical analysis}

In order to make the main characteristic inside the model scramjet clear, an analytical method was developed based on the calculation of one-dimensional equations connected to a Chemkin subroutine of Plug Flow Reactor. The kerosene combustion model has 17 species and 34 step chemical reactions. The flow is supposed to be uniform at cross section. The wall temperature assumes to be a constant value. The static temperature of main flow is correlated from experimental data, so that the other parameters such as pressure, velocity, Mach number and heat release rate can be calculated from the equations.

Figure 10(a) shows the analysis results of the model with combination injections $\mathrm{S} 2(E R=0.79)$ and $\mathrm{C} 2$ $(E R=0.32)$. The solid line is the static pressure along the model, and the dot is the experimental static pressure. The numerical analysis gains good agreement with the experimental data. The line with hollow triangle is the Mach number along the model. It decreases when pressure increases to the peak value, and then it gets the lowest value about 1.26 at first cavity region. The dash line is the dimensionless reaction heat release rate (divided by the inlet total enthalpy) along the model. It decreases sharply along the flow direction until the second fuel is injected and the trend becomes gentle. The combustion efficiency (thermal releases increment/fuel caloric heat capacity) of engine is about $64 \%$.

Figure 10(b) shows the results of the fuel injection only at S3 $(E R=0.79)$. The peak pressure is about $8 \%$ lower than the case of $\mathrm{S} 2+\mathrm{C} 2$, and the peak heat release rate is $16 \%$ lower than it. The total combustion efficiency decreases to $46 \%$. Different heat release rates

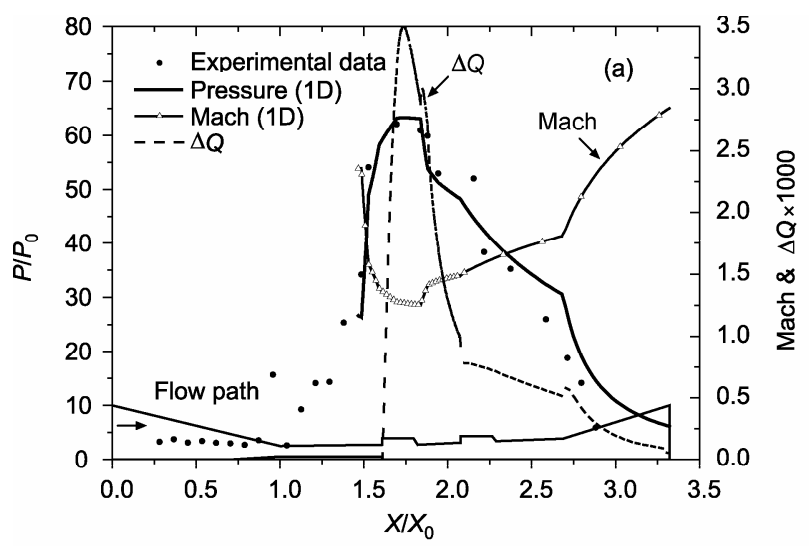

along the model show that the second fuel injection helps to maintain a high pressure in combustor at the first cavity region, and makes it benefit more for reaction.

The mole fractions of species along the model at case of $\mathrm{S} 2+\mathrm{C} 2$ are shown in Figure 11(a). The mole fraction of $\mathrm{CO}_{2}$ increases rapidly at the first cavity, and then increases slowly when passing through the cavity region. The mole fraction of $\mathrm{H}_{2} \mathrm{O}$ resembles the $\mathrm{CO}_{2}$. The final mole fractions of these two products determine the total heat release rate. There are also some unburned fuels, semi-production like $\mathrm{CO}$ in the exhaust. Hence they bring additional heat release loss for engine potential performance.

Figure 11(b) shows the mole fraction of the species along the model at the case of S3. The mole fractions of $\mathrm{CO}_{2}$ and $\mathrm{H}_{2} \mathrm{O}$ are lower than the case of $\mathrm{S} 2+\mathrm{C} 2$, though they have the same fuel equivalence ratio at the first cavity region. The heat release rate decreases and Mach number increases at the same region in comparison with the case of $\mathrm{S} 2+\mathrm{C} 2$.

The pressure in the case of $\mathrm{S} 2+\mathrm{C} 2$ is higher than the case of S3, which may be the fuel injection at the second fuel position increasing the local temperature and pressure. The pressure wave propagates to the upstream through the boundary or cavity, and then increases the temperature of the first fuel injection region. Finally the steady combustion at the first injection region gains higher temperature and pressure than the single fuel injection state at the same equivalence ratio, because the flow properties have changed. Because the chemical reaction is not a linear process, the pressure along the combustor declines rapidly under constant diverging angle.

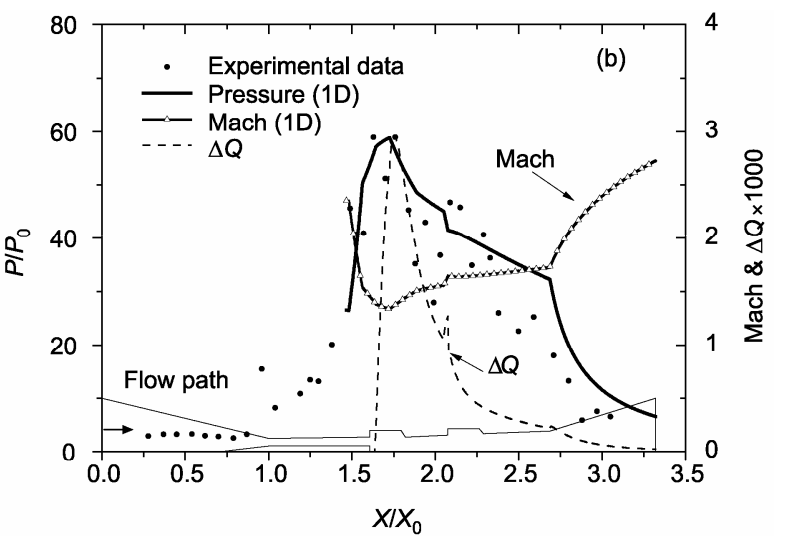

Figure 10 Numerical analysis results of static pressure, Mach and heat production. (a) Two-stage fuel injection $\mathrm{S} 2+\mathrm{C} 2, E R=0.79+0.32$; (b) one-stage fuel injection $\mathrm{S} 3, E R=0.79$. 

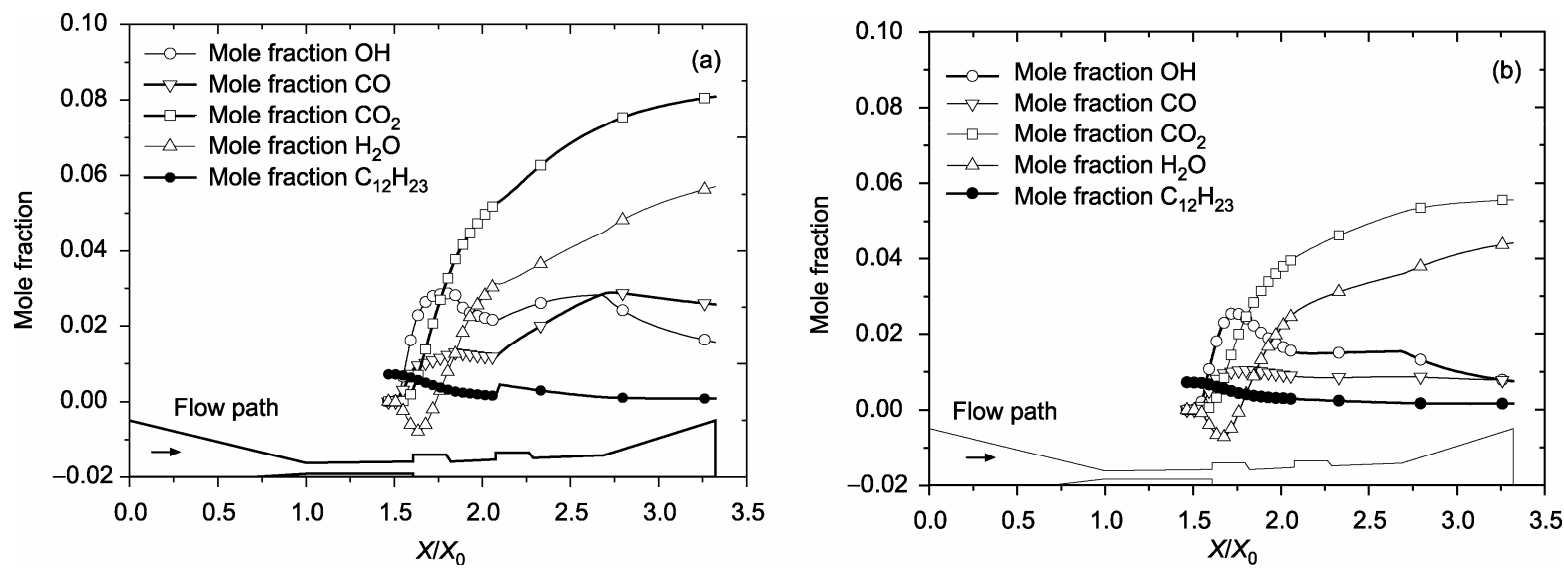

Figure 11 Numerical analysis results of gas components. (a) Two-stage fuel injection S2+C2, $E R=0.79+0.32$; (b) one-stage fuel injection S3, $E R=0.79$.

In our model, the nozzle cannot be designed for fully expansion and some semi-productions also increase heat energy losses. If the pressure can keep constant in combustor, and combine two-stage or multi-stage fuel injections with a reasonable engine flowpath design, the better performance can be obtained further.

\section{Conclusions}

The performance of the cavity-based scramjet model with different fuel injections strategy was investigated in a high-enthalpy free-jet tunnel. A numerical analysis with chemical reaction revealed the mechanics of per-

1 McClinton C R, Rausch V L, Nguyen L T, et al. Preliminary X-43 flight test results. Acta Astronaut, 2005, 57: 266-276

2 Smart M K, Hass N E, Paul A. Flight data analysis of the hyshot 2 scramjet flight experiment. AIAA J, 2006, 44: 2366-2375

3 Bertin J J, Cummings R M. Fifty years of hypersonics: Where we have been, where we are going. Prog Aerosp Sci, 2003, 39: $511-536$

4 Petrova M V, Williams F A. A small detailed chemical-kinetic mechanism for hydrocarbon combustion. Combust Flame, 2006, 144: $526-544$

5 Simmie J M. Detailed chemical kinetic models for the combustion of hydrocarbon fuels. Prog Energ Combust, 2003, 29: 599-634

6 Vinogradov V A, Kobigsky S A, Petrov M D. Experimental investigation of kerosene fuel combustion in supersonic-flow. J Propul Power, 1995, 11: 130-134

7 Yu G, Li J G, Chang X Y, et al. Fuel injection and flame stabilization in a liquid-kerosene-fueled supersonic combustor. J Propul Power, 2003, 19: 885-893

8 Yu G, Li J G, Zhang X Y, et al. Experimental investigation on flameholding mechanism and combustion performance in hydrogen-fueled supersonic combustors. Combust Sci Tech, 2002, 174: $1-27$

9 Ben-Yakar A, Hanson R K. Cavity flame-holders for ignition and formance improvement under two-stage fuel injections.

Strut was an effective tool to increase the engine performance for the cavity based scramjet. The engine can work at wider range of fuel equivalence ratio. Positive thrust was gained under test condition.

Higher combustion efficiency was obtained with twostage fuel injections. The heat release rate was higher than the case of single fuel injection.

The one dimensional analysis indicated that the large amount of chemical energy was lost by incomplete reaction, so the key problem for increasing scramjet engine performance further was to increase the chemical reaction rate and decrease semi-productions.

flame stabilization in scramjets: An overview. J Propul Power, 2001, 17: $869-877$

10 Gruber M R, Baurle R A, Mathur T, et al. Fundamental studies of cavity-based flameholder concepts for supersonic combustors. J Propul Power, 2001, 17: 146-153

11 Gruber M R, Donbar J M, Carter C D. Mixing and combustion studies using cavity-based flameholders in a supersonic flow. J Propul Power, 2004, 20: 769-778

12 Hermanson J C, Papas P, Kay I W. Structure and penetration of a supercritical-fluid jet in supersonic-flow. J Propul Power, 1994, 10: $387-394$

13 Mitani T, Kouchi T. Flame structures and combustion efficiency computed for a Mach 6 scramjet engine. Combust Flame, 2005, 142 $187-196$

14 Kobayashi K, Tomioka S, Kato K, et al. Performance of a dual-mode combustor with multistaged fuel injection. J Propul Power, 2006, 22: 518-526

15 Tomioka S, Kobayashi K, Kudo K, et al. Performance of supersonic combustors with fuel injection in diverging section. J Propul Power, 2006, 22: $111-119$

16 Billig F S. Research on supersonic combustion. J Propul Power, 1993, 9: 499-514 